\title{
Reducción de la demanda química de oxígeno, coliformes, mohos y levaduras en mucílago de café mediante electrocoagulación
} Reduction in chemical oxygen demand, coliforms, molds and yeast in coffee mucilage through electrocoagulation Redução da demanda química de oxigênio, coliformes, mofos e leveduras em mucilagem de café por eletrocoagulação

\author{
Luis Felipe Orozco ${ }^{1}$, Katherin Castro-Ríos ${ }^{2} \&$ Gonzalo Taborda 0campo ${ }^{3}$ \\ ${ }^{1}$ Licenciado en Biología y Química. ${ }^{2}$ Ingeniera de Alimentos, Candidata a Doctora en Ciencias Agra- \\ rias y Especialista en Desarrollo Agroindustrial. ${ }^{3}$ Licenciado en Biología y Química, Especialista en \\ Ciencia y Tecnología de los Alimentos, Magister en Ciencias Químicas y Doctor en Ciencias Químicas \\ ${ }^{1}$ Departamento de Química. ${ }^{2}$ Facultad de Ciencias Agropecuarias. ${ }^{3}$ Facultad de Ciencias Exactas. \\ 1,2,3 Universidad de Caldas, Manizales, Colombia \\ 1'luis.orozco@ucaldas.edu.co, ${ }^{2}$ katherin.castro@ucaldas.edu.co. ${ }^{3}$ gtaborda@ucaldas.edu.co
}

\section{Resumen}

El mucílago y la pulpa de café, son subproductos semilíquidos involucrados en la generación de aguas residuales con alta concentración de materia orgánica y diversas especies de microorganismos, afectando negativamente la eficiencia de los tratamientos tradicionales, que requieren hasta cinco meses para la descontaminación total de este tipo de aguas. Esto demanda la evaluación de diferentes técnicas de tratamiento, que mejoren la eficiencia de los procesos tradicionales. Se evaluó la electrocoagulación con electrodos $\mathrm{Fe} / \mathrm{Al}$, $2.3 \mathrm{~A}$ y pH natural, en la reducción de la demanda química de oxígeno y algunos microorganismos, presentes en mucílago de café. El proceso electroquímico propició una remoción máxima de $93 \%$ para bacterias coliformes, mohos y levaduras, en un tiempo de tratamiento de 50 min. La reducción de la demanda química de oxígeno fue $32 \%$ para la muestra sin diluir, $45 \%$ para la muestra diluida al $50 \%(\mathrm{v} / \mathrm{v})$ y $51 \%$, para las muestra diluida al $25 \%(\mathrm{v} / \mathrm{v})$; indicando una mejor eficiencia con la disminución de la materia orgánica. El consumo energético fue inferior a los $0.083 \mathrm{kWh} / \mathrm{m}^{3}$, para las muestras analizadas. Esta técnica es una alternativa adecuada para el pre-tratamiento o reutilización de aguas contaminadas con mucílago de café.

Palabras clave: bacterias, electroquímica, hongos, materia orgánica, subproductos de café.

\section{Abstract}

Coffee pulp and mucilage are semi-liquid by-products involved in the generation of residual waters with a high concentration of organic matter and diverse species of microorganisms which negatively affect the efficiency of traditional treatment and require up to five months for total decontamination of these waters. This demands the testing of different treatment methods that can improve the efficiency of traditional processes. Electrocoagulation was tested with $\mathrm{Fe} / \mathrm{Al}$ electrodes, $2.3 \mathrm{~A}$ and natural $\mathrm{pH}$ in a reduction in chemical oxygen demand and other microorganisms present in the coffee mucilage. The electrochemical process produced a 
maximum removal of $93 \%$ for coliform bacteria, molds and yeasts with a treatment time of $50 \mathrm{~min}$. The reduction in chemical oxygen demand was $32 \%$ for the undiluted sample, $45 \%$ for the sample diluted to $50 \%(\mathrm{v} / \mathrm{v})$, and $51 \%$ for sample diluted to $25 \%(\mathrm{v} / \mathrm{v})$; indicating there is an increase in efficiency with a decrease in organic matter. The energy consumption was less than $0.083 \mathrm{kWh} / \mathrm{m}^{3}$ for the samples analyzed. This method is a viable alternative for the pre-treatment or reutilization of waters contaminated with coffee mucilage.

Key-words: bacteria, electrochemical, molds, organic matter, coffee by-products

\section{Resumo}

A mucilagem e polpa de café são subprodutos semilíquidos envolvidos na geração de efluentes com elevado teor de matéria orgânica e de várias espécies de microrganismos, impactando adversamente a eficácia dos tratamentos tradicionais, que precisam de até cinco meses para a descon- taminação total deste tipo de água. Isto requer a avaliação de diferentes técnicas de tratamento, que melhorem a eficiência dos processos tradicionais. Avaliou-se a eletrocoagulação com eletrodos Fe/Al, 2.3 e pH natural, na redução da demanda química de oxigênio e alguns micro-organismos presentes na mucilagem do café. O processo eletroquímico levou a uma remoção máxima de 93\% para bactérias coliformes, mofos e leveduras, em um tempo de tratamento de 50 min. A redução da demanda química de oxigênio foi de $32 \%$ para a amostra não diluída, 45\% para a amostra diluída a $50 \%(\mathrm{v} / \mathrm{v})$ e $51 \%$ para a amostra diluída a $25 \%$ $(\mathrm{v} / \mathrm{v})$, indicando melhor eficiência com a redução do material orgânico. O consumo de energia foi inferior a $0.083 \mathrm{kWh} / \mathrm{m}^{3}$ para as amostras analisadas. Esta técnica é uma alternativa adequada para o pré-tratamento ou reutilização de águas contaminadas com mucilagem de café.

Palavras-chave: bactérias, eletroquímica, fungos, matéria orgânica, subprodutos do café.

\section{Introducción}

El fruto de café se encuentra compuesto de cáscara, pulpa, mucílago, pergamino, película plateada y semilla. Para retirar estas capas y obtener el producto de importancia comercial, es necesario someter a este a diversas etapas conocidas como beneficio, generando diversos productos secundarios. El mucílago de café, es un subproducto semilíquido compuesto principalmente por polisacáridos, proteínas y polifenoles (Avallone, Guiraud, Guyot, Olguin, \& Brillouet, 2000; Mussatto, Machado, Martins, \& Teixeira, 2011); además alberga microorganismos de los géneros Enterobacter, Staphylococos, Serratia, Candida, Torulopsis, Rhodotorula, Escherichia y Citrobacter (Blandón-Castaño, Dávila-Arias, \& RodríguezValencia, 1999). Sus características físico-químicas y biológicas lo convierten en un subproducto complejo y altamente contaminante; implicado en la generación de aguas residuales con altos porcentajes de sólidos y demanda química de oxígeno (DQO), con reportes entre 1500 a 101200 $\mathrm{mgO}_{2} / \mathrm{L}$, dependiendo de la etapa del proceso y la tecnología empleada (Chanakya \& Alwis, 2004; Olvera \& Gutiérrez, 2010; Rodríguez, Silva, \& Boizán, 2000; Selvamurugan, Doraisamy, Maheswari, \& Nandakumar, 2010; Zambrano-Franco \& Cárdenas-Cárdenas, 2000).

El tratamiento anaerobio es empleado tradicionalmente para la remoción de materia orgánica en las aguas residuales del beneficio del café, sin embargo esta técnica demanda un largo tiempo de tratamiento, lo que incrementa los costos y eficiencia del proceso. Esto se observa en trabajos como el de Rodríguez et al. (2000) que determinaron la biodegradabilidad anaerobia de las aguas residuales procedentes del beneficio húmedo del café, empleando como inóculo el estiércol de vacuno y lodos de laguna de estabilización, alcanzando una reducción de la DQO menor al 40\%. 
En un estudio similar empleando fluido ruminal vacuno como inóculo para la depuración de agua del despulpado, alcanzaron una remoción de $91.2 \%$ con $\mathrm{pH}$ de 4.6 y $28{ }^{\circ} \mathrm{C}$ en 16 días (Olvera \& Gutiérrez, 2010). Otros sistemas más robustos como el Sistema Modular de Tratamiento Anaerobio (SMTA), desarrollado por Cenicafé para el tratamiento de las aguas residuales del lavado, han reportado remociones de DQO y $\mathrm{DBO}_{5}$ (Demanda bioquímica de oxígeno) inferiores al $80 \%$, pero todo el proceso requiere un tiempo aproximado de 5 meses (Zambrano-Franco, Isaza-Hinestroza, Rodríguez-Valencia, \& Posada, 1999).

El tratamiento de aguas residuales mediante electrocoagulación es una alternativa que reduce o remueve contaminantes en un medio acuoso, mediante el paso de una corriente eléctrica a través de electrodos de hierro o aluminio, generando de forma electroquímica iones coagulantes en el ánodo que desestabilizan los contaminantes, para luego formar flocs que sedimentan o flotan (MoIlah, Morkovsky, Gomes, Kesmez, Parga, \& Cocke, 2004). Esta técnica ha evidenciado un potencial en la remoción de contaminantes de aguas residuales de la agroindustria y la industria de alimentos (Drogui, Asselin, Brar, Benmoussa, \& Blais, 2008; Kobya \& Delipinar, 2008; Papastefanakis, Mantzavinos, \& Katsaounis, 2010; Tchamango, Nanseu-Njiki, Ngameni, Hadjiev, \& Darchen, 2010), y recientemente un efecto en la reducción del contenido de microorganismos (Gao, Yang, Tian, Ma, Tu, \& Du, 2010; Ghernaout, Badis, Kellil, \& Ghernaout, 2008; Martínez-Huitle \& Brillas, 2008).

Las características del mucílago del café, implican la evaluación de nuevas técnicas que reduzcan eficientemente los contaminantes físico-químicos y biológicos, proporcionando alternativas de reutilización o pre-tratamiento de los residuos líquidos del beneficio de café. El objetivo del presente trabajo es la evaluación de la electrocoagulación y algunos parámetros intrínsecos del proceso, en la reducción de DQO y microorganismos (bacterias coliformes, mohos y levaduras) en mucílago de café.

\section{Materiales y métodos}

\section{Localización}

Se recolectaron muestras provenientes de dos fincas del municipio de Manizales (Colombia), con condiciones similares de procesamiento del café cereza, la temperatura promedio de la zona es de $23^{\circ} \mathrm{C}$ y pluviosidad máxima de $280 \mathrm{~mm} / \mathrm{mes}$. Las muestras fueron almacenadas entre $24-48 \mathrm{~h}$ a $4^{\circ} \mathrm{C}$, hasta el momento de ser electrocoaguladas. Las características físico-químicas del mucílago de café recolectado se muestran en la Tabla 1.

Tabla 1. Características físico-químicas del mucílago de café antes de la electrocoagulación.

\begin{tabular}{lc}
\hline \multicolumn{1}{c}{ Parámetro } & Valor \\
\hline Humedad (\%) & 96.20 \\
\hline Materia seca (\%) & 3.80 \\
\hline Nitrógeno total (\%) & 2.08 \\
\hline Proteína bruta (\%) & 13.00 \\
\hline Fósforo (\%) & 0.17 \\
\hline Potasio (\%) & 0.44 \\
\hline Hierro (mg/L) & 264.30 \\
\hline Cobre (mg/L) & 19.20 \\
\hline Manganeso (mg/L) & 44.10 \\
\hline Zinc (mg/L) & 18.20 \\
\hline DQO (mg/L) & 67500 \\
\hline Sólidos Totales (mg/L) & 46680 \\
\hline Conductividad (mS/cm) & $4.2\left(22.7^{\circ} \mathrm{C}\right)$ \\
\hline pH & 3.56 \\
\hline
\end{tabular}

\section{Procedimiento experimental}

Los experimentos electroquímicos fueron realizados en un reactor tipo batch, consistente en un beaker de vidrio de $500 \mathrm{~mL}$, equipado con dos electrodos de hierro (ánodos) y dos electrodos de 
aluminio (cátodos), con área efectiva de $44 \mathrm{~cm}$ y una distancia inter-electródica de $1.0 \mathrm{~cm}$ (Figura 1). Los electrodos se conectaron a una fuente de corriente directa (MCP Lab electronics) de $30 \mathrm{~V} \mathrm{y}$ $20 \mathrm{~A}$. La intensidad de corriente aplicada fue 2.3 $\mathrm{A}, \mathrm{pH}$ natural, sin adición de electrolito soporte a la muestra, debido a la conductividad presentada (Tabla 1), estos parámetros fueron seleccionados con base a resultados previos (Castro-Ríos, Orozco, \& Taborda, 2012a, 2012b). Adicionalmente, se realizó un estudio modelo utilizando los mismos parámetros, con el fin de determinar la eficiencia del proceso electroquímico según la concentración de materia orgánica presente, empleando diluciones al $50 \%(\mathrm{v} / \mathrm{v})$ y $25 \%(\mathrm{v} / \mathrm{v})$ de la matriz inicial. Los datos fueron analizados mediante estadística descriptiva y análisis de varianza, realizado con el software Statgraphics ${ }^{\circledR}$ plus.

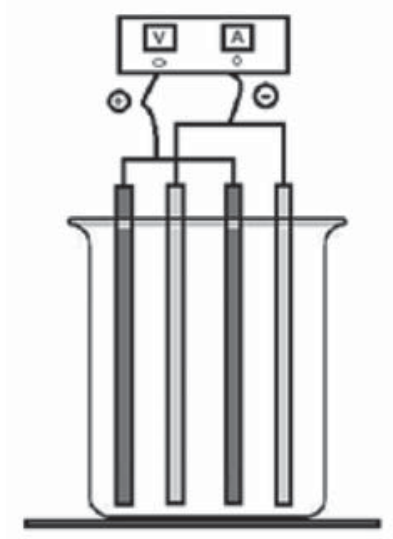

Figura 1. Esquema reactor electroquímico

\section{Análisis de las muestras tratadas}

La DQO, fue medida empleando el método de reflujo cerrado por técnica colorimétrica, según procedimiento APHA 5220 D (APHA, 1999), luego fue determinada la concentración de DQO en un fotómetro Spectroquat $₫$ Nova 60 (Merck, Alemania). Las medidas de $\mathrm{pH}$, se realizaron empleando un potenciómetro Metrohm Mod. E-744 (Metrohm, Suiza). Las muestras para el análisis microbiológico fueron asépticamente pipeteadas, y posteriormente diluidas hasta $10^{-3}$, en agua peptonada (Oxoid). Luego se inocularon mediante la técnica de siembra en superficie en agar EMB (Oxoid) y agar YGC (Scharlau). Las muestras se incubaron a $37^{\circ} \mathrm{C}$ durante $24-48 \mathrm{~h}$ para coliformes, y $25^{\circ} \mathrm{C}$ durante 5 días para mohos y levaduras. Finalmente se efectuó el conteo de las colonias.

\section{Consumo energético}

El consumo de energía eléctrica es un parámetro económico muy importante en el proceso electroquímico y fue calculado usando la ecuación (1) (Akbal \& Camcl, 2011):

$$
\mathbf{E}=\frac{\text { U.I.t }}{\mathbf{V}}
$$

Donde $E$ es el consumo de energía $\left(\mathrm{kWh} / \mathrm{m}^{3}\right), U$ es el voltaje aplicado (V), I es la intensidad de corriente (A), $t$ es el tiempo de EC (h), y $V$ es el volumen del agua residual tratada $(\mathrm{L})$.

\section{Resultados}

\section{Reducción de DQO presente en mucílago de café}

La reducción de las sustancias orgánicas disueltas en mucílago de café fue confirmada por la disminución en la DQO, y la diferencia estadística evaluada mediante análisis de varianza $(p<0.05)$ y contraste de Fisher (LSD, Least significant difference test) de los resultados previos y posteriores al proceso electroquímico. El valor promedio de DQO antes de la electrocoagulación fue 67500 $\mathrm{mg} / \mathrm{L}$, el cual fue reducido a $45825 \mathrm{mg} / \mathrm{L}$ (50 min), correspondiente a $32.11 \%$ de reducción (Figura 2). En lo relacionado con el pH de la solución se aprecia un aumento de 3.56 a 5.32 (Figura 3).

Los resultados de las diluciones del mucílago de café, se observan en la Figura 4, allí se evidencia el incremento del porcentaje de reducción de DQO, a mayor dilución. La máxima reducción, fue 51.16\% para la dilución al $50 \%(\mathrm{v} / \mathrm{v})$ y un $45.34 \%$ para la dilución al 25\% (v/v), en 50 min. Los valores de DQO inicial para las muestras diluidas al 50 y $25 \%$ (v/v) fueron $32250 \mathrm{mg} / \mathrm{L}$ y $14750 \mathrm{mg} / \mathrm{L}$ respectivamente. 


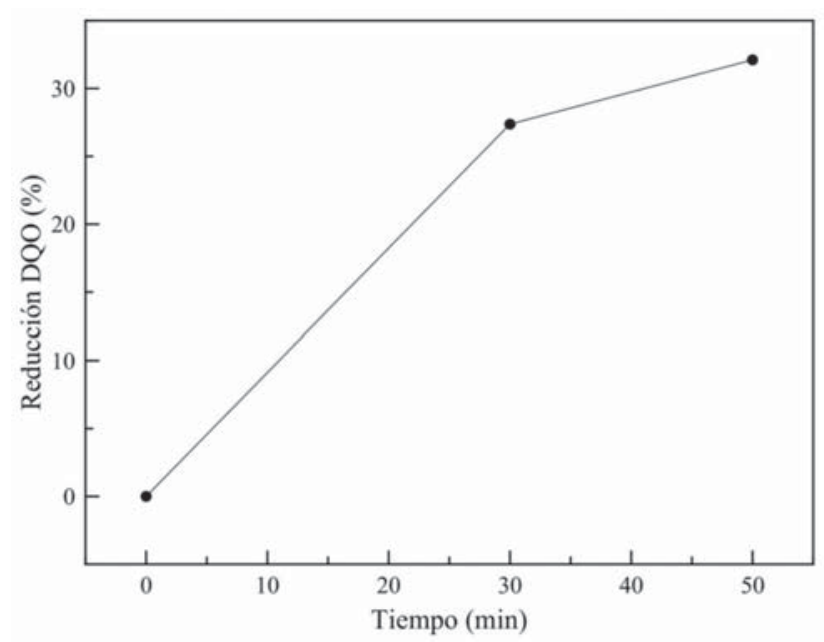

Figura 2. Reducción de DQO

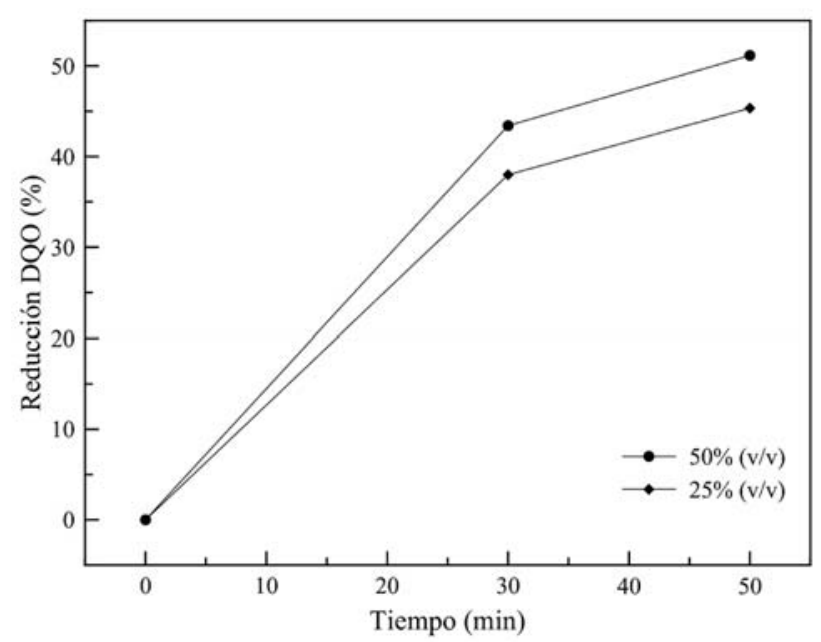

Figura 4. Reducción de DQO en muestras diluidas

\section{Reducción de mohos, levaduras y coliformes presentes en mucílago de café}

La Figura 5, muestra la reducción de microorganismos por electrocoagulación, en esta se observa que el $70 \%$ de la reducción de mohos y levaduras, y el $90 \%$ de bacterias coliformes ocurre durante los primeros $30 \mathrm{~min}$ del proceso de electrocoagulación. La reducción máxima para ambos microorganismos, fue $93 \%$ en $50 \mathrm{~min}$.

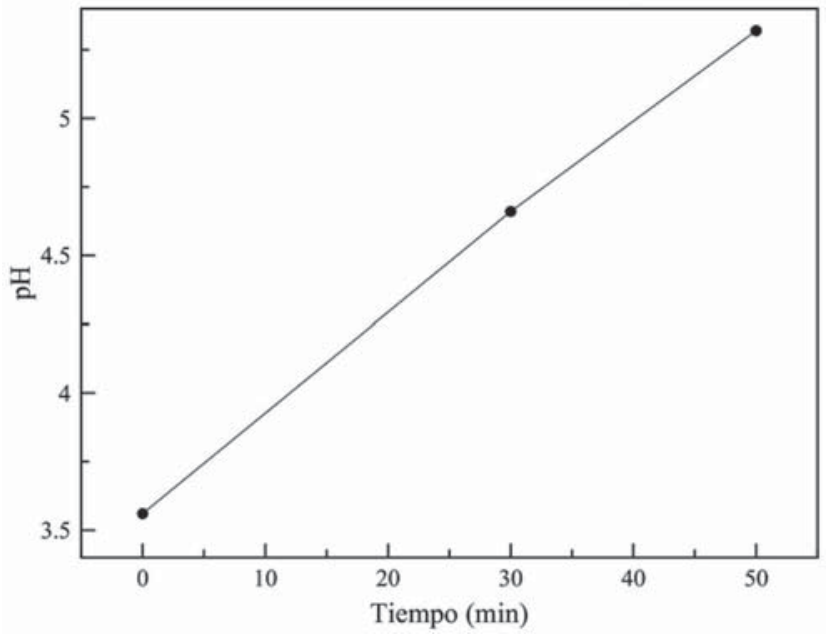

Figura 3. Variación del pH durante el tratamiento electroquímico

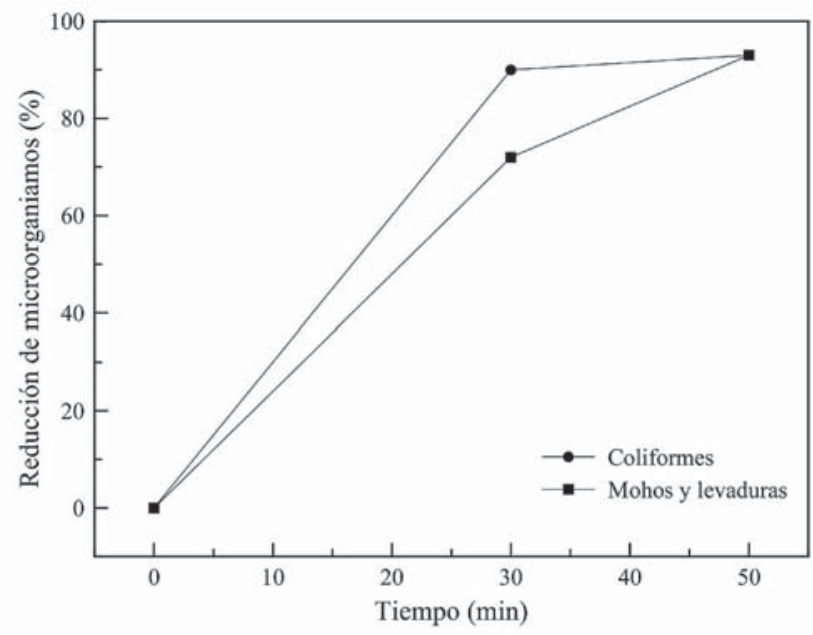

Figura 5. Reducción de microorganismos

\section{Consumo energético}

Se analizó el consumo de energía eléctrica empleando la ecuación (1), para lo cual se utilizó el potencial $(\mathrm{V})$ registrado durante el tiempo de electrocoagulación y los valores de los parámetros de corriente, tiempo, $\mathrm{pH}$ y volumen citados anteriormente. El consumo energético obtenido fue $0.0368 \mathrm{kWh} / \mathrm{m}^{3}, 0.0524 \mathrm{kWh} / \mathrm{m}^{3}$ y $0.0827 \mathrm{kWh} / \mathrm{m}^{3}$ para la muestra sin diluir, diluida al $50 \%(\mathrm{v} / \mathrm{v})$ y diluida al $25 \%(\mathrm{v} / \mathrm{v})$ respectivamente. 


\section{Discusión y conclusiones}

Los resultados muestran, que la electrocoagulación puede reducir hasta un $32 \%$ la cantidad de materia orgánica presente en el mucílago de café con los parámetros evaluados, aunque los porcentajes de reducción de DQO son menores en comparación con estudios similares (Agustin, Sengpracha, \& Phutdhawong, 2008; Khoufi, Feki, \& Sayadi, 2007; Tezcan Ün, Ugur, Koparal, \& Bakır Ögütveren, 2006); debido al alto contenido de materia orgánica en el mucílago de café. Esto se puede comprobar con los resultados de las muestras diluidas (Figura 4), ya que al disminuir la concentración de materia orgánica, es posible obtener porcentajes de reducción de DQO mayores.

En lo relacionado con el pH de la solución, se aprecia un aumento de 3.56 a 5.32 (Figura 3). Esto podría ser explicado por la formación de iones hidroxilo y de $\mathrm{Fe}^{+}{ }_{(\text {ac) }}$ conforme las reacciones (2-4):

Reacción ánodo:

$$
\mathrm{Fe} \rightarrow \mathrm{Fe}^{3+}+3 \mathrm{e}^{-}
$$

Reacción cátodo:

$$
2 \mathrm{H}_{2} \mathrm{O}+2 \mathrm{e}^{-} \rightarrow 2 \mathrm{OH}^{-}+\mathrm{H}_{2}
$$

Reacción total:

$$
2 \mathrm{Fe}+6 \mathrm{H}_{2} \mathrm{O} \rightarrow 2 \mathrm{Fe}(\mathrm{OH})_{3}+3 \mathrm{H}_{2}
$$

El hierro también puede reaccionar directamente con compuestos orgánicos que contienen átomos con carga negativa, o formar complejos de hidróxidos poliméricos tales como: $\mathrm{Fe}\left(\mathrm{H}_{2} \mathrm{O}\right)_{6}{ }_{6}^{+}$, $\mathrm{Fe}\left(\mathrm{H}_{2} \mathrm{O}\right)_{5}(\mathrm{OH})^{+}, \quad \mathrm{Fe}\left(\mathrm{H}_{2} \mathrm{O}\right)_{4}(\mathrm{OH})_{2}^{+}$, que dependen del $\mathrm{pH}$ del medio acuoso. Estos hidróxidos, polihidróxidos o compuestos polihidroximetálicos tienen fuerte afinidad por las partículas dispersas, así como contra-iones, lo cual provoca la coagulación (Mollah et al., 2004).
La reducción de microorganismos muestra un proceso en dos etapas (Figura 5). La etapa inicial promueve una rápida reducción y se presenta entre los 25 y $30 \mathrm{~min}$, y la segunda etapa se caracteriza por una reducción más lenta. El porcentaje máximo de reducción fue $93 \%$ para los dos grupos de microorganismos, un valor similar al obtenido por Ghernaout, et al. (2008) empleando electrodos de aluminio y acero en un agua residual contaminada con la bacteria E.coli. La mínima eficiencia del proceso se presentó en el menor tiempo de tratamiento, con valores de $90 \%$ para la reducción de coliformes y $72 \%$ para la reducción de mohos y levaduras; por lo tanto el aumento en el tiempo de tratamiento, mejora la reducción de microorganismos, esto coincide con los resultados presentados por otros autores (Azarian, Mesdaghinia, Vaezi, Nabizadeh, \& Nematollahi, 2007; Gao et al., 2010).

El proceso de electrocoagulación bajo las condiciones estudiadas, generó resultados satisfactorios en la reducción de DQO, coliformes, mohos y levaduras, perfilándose como una alternativa de pre-tratamiento o reutilización de aguas contaminadas con mucílago de café.

\section{Agradecimientos}

Los autores expresan su agradecimiento a la Universidad de Caldas, al programa Jóvenes Investigadores e Innovadores "Virginia Gutiérrez de Pineda" de Colciencias y al equipo involucrado en las fincas de café, por el apoyo para el desarrollo de esta investigación.

\section{Literatura citada}

1. Agustin, M., Sengpracha, W., \& Phutdhawong, Weerachai. (2008). Electrocoagulation of Palm Oil Mill Effluent. International Journal of Environmental Research and Public Health, 5(3), 177-180.

2. Akbal, F., \& Camcı, S. (2011). Copper, chromium and nickel removal from metal plating wastewater by electrocoagulation. Desalination, 269(1-3), 214-222. 
3. APHA. (1999). Standard Methods for the Examination of Water and Wastewater (Version 19th). Washington DC.

4. Avallone, Guiraud, J., Guiraud, P., Guyot, B., Olgin, E. \& Brillouet, M. (2000). Polysaccharide Constituents of Coffee-Bean Mucilage. Journal of Food Science., 65(8), 1308-1311.

5. Azarian, Mesdaghinia, A., Vaezi, F., Nabizadeh, R. \& Nematollahih, D. (2007). Algae Removal by Electrocoagulation Process, Application for Treatment of the Effluent from an Industrial Wastewater Treatment Plant. Iranian J Publ Health., 36(4), 57-64.

6. Blandón-Castaño, G., Dávila-Arias, M.T., \& RodríguezValencia, N. (1999). Caracterización microbiológica y físico-química de la pulpa de café sola y con mucílago en proceso de compostaje. Cenicafé., 50(1), 5-23.

7. Castro-Ríos, K., Orozco, L. F., \& Taborda, G. (2012a). Reducción de la demanda química de oxígeno en mucílago de café mediante electrocoagulación. XXVII Congreso de la Sociedad Mexicana de Electroquímica llevado a cabo en Toluca, México.

8. Castro-Ríos, K., Orozco, L. F., \& Taborda, G. (2012b). Remoción de microorganismos presentes en mucílago de café mediante electrocoagulación. V Seminario Colombiano de Electroquímica llevado a cabo en Medellín, Colombia.

9. Chanakya, H. N., \& Alwis, A. A. P. De. (2004). Environmental issues and management in primary coffee procesing. Process Safety and Environmental Protection. (84 (B4)), 291-300.

10. Drogui, P., Drogui, P.; Asselin, M.; Brar, S. K.; Benmoussa, H. \& Blais, J. F. (2008). Electrochemical removal of pollutants from agro-industry wastewaters. Separation and Purification Technology.(61), 301-310.

11. Gao, Gao, S., Yang, J., Tian, J., Ma, F., Tu, G. \& Du, M. (2010). Electro-coagulation-flotation process for algae removal. Journal of Hazardous Materials.(177), 336-343.

12. Ghernaout, Badis, A., Kellil, A., Ghernaout, D. \& Ghernaout, B. (2008). Application of electrocoagulation in Escherichia coli culture and two surface waters. Desalination.(219), 118-125.

13. Khoufi, S., Feki, F., \& Sayadi, S. (2007). Detoxification of olive mill wastewater by electrocoagulation and sedimentation processes. Journal of Hazardous Materials, 142 (1-2), 58-67.

14. Kobya, M., \& Delipinar, S. (2008). Treatment of the baker's yeast wastewater by electrocoagulation. Journal of Hazardous Materials.(154), 1133-1140.
15. Martínez-Huitle, C. A., \& Brillas, Enric. (2008). Electrochemical Alternatives for Drinking Water Disinfection. Angew. Chem. Int. (47), 1998-2005.

16. Mollah, M. Mollah, M.; Morkovsky, P.; Gomes, J.; Kesmez, M.; Parga, J. \& Cocke, D. (2004). Fundamentals, present and future perspectives of electrocoagulation. Journal of Hazardous Materials.(B114), 199-210.

17. Mussatto, S.; Machado, E.; Martins, S. \& Teixeira, J. (2011). Production, Composition, and Application of Coffee and Its Industrial Residues. Food Bioprocess Technology(4), 661- 672 .

18. Olvera, J., \& Gutiérrez, J. I. (2010). Biodegradación anaerobia de las aguas generadas en el despulpado del café Revista Colombiana de Biotecnología., 12(2), 230-239.

19. Papastefanakis, N., Mantzavinos, D., \& Katsaounis, A. (2010). DSA electrochemical treatment of olive mill wastewater on $\mathrm{Ti} / \mathrm{RuO}_{2}$ anode. Journal of Applied Electrochemistry.(40), 729-737.

20. Rodríguez, S. P., Silva, R. M. Perez, \& Boizán, M. F. (2000). Estudio de la biodegradabilidad anaerobia de las aguas residuales del beneficio húmedo del café. Interciencia., 25(8), 386-390.

21. Selvamurugan, Doraisamy, P.; Maheswari, M.; Selvamurugan, M. \& Nandakumar, N. (2010). High rate anaerobic treatment of coffee procesing wastewater using upflow anaerobic hybrid reactor. Iran. J. Environ. Health. Sci. Eng., 7(2), 129-136.

22. Tchamango, Nanseu-Njiki, Ch.; Ngareni, E.; Hadjiev, D.; Darchen, A. \& Tchamango, S. (2010). Treatment of dairy effluents by electrocoagulation using aluminium electrodes. Science of the Total Environment.(408), 947-952.

23. Tezcan Un, U., Ugur, S., Koparal, A.S. \& Baker Ogutceren, U. Electrocoagulation of olive mill was tewater S. J. Separation and Purification Technology. (2006); 52: 136 - 141.

24. Zambrano-Franco, D. A., \& Cárdenas-Cárdenas, J. (2000). Manejo y tratamiento primario de lixiviados producidos en la tecnología Becolsub. Avances Técnicos. (280), 1-8.

25. Zambrano-Franco, Zambrano-Franco, D.; Isaza, J.; Rodríguez, N. \& López, U. (1999). Tratamiento de aguas residuales del lavado de café Boletín Técnico. (pp. 30). Chinchiná: Cenicafé. 